\title{
Discourse Markers as Triggers of Code-switching in EFL Classes
}

\author{
Mingfa Yao \\ School of Applied Foreign Languages, \\ Zhejiang International Studies University, Hangzhou, China. \\ mingfayao@163.com
}

\begin{abstract}
In secondary EFL classes, teachers often switch codes when they express their ideas that students do not understand. Those switches are often triggered by such discourse markers as Well, Ok in English, and Good in Chinese. It seems that these discourse markers mostly occur at the beginning or at the end of the digression, with topics shifting. In this paper, four of these discourse makers are described in the structuring functions within ongoing teachers' discourse in EFL classroom, and examples from the corpora are given, indicating that the different functions in discourse strategies exist between English and Chinese.
\end{abstract}

Keywords: Discourse markers; triggers; code-switching; EFL classes.

\section{INTRODUCTION}

Discourse markers, defined as a linguistic device that speakers use to signal how the upcoming unit of speech or text relates to the current discourse state (Schiffrin 1987), are frequently used in utterances of code-switching by the teachers observed in language classrooms. This paper refers to discourse marker as the expressions in teachers' discourse that used pragmatically, with a structural and organizational function in classroom. It is partly based on Redeker's definition of what she calls "discourse operators", namely " a word or phrase-for instance a conjunction, adverbial, comment clause, interjection- that is uttered with the primary function of bringing to the listeners' attention a particular kind of linkage of the upcoming utterance with the immediate discourse context"(Redeker, 1991: 1168). In teachers discourse in EFL classrooms, many code-switches are triggered by discourse markers such as, $O K$, 好(Good), Well, etc. These markers are discussed when researchers analyze the structure patterns of code-switching. More about functions of discourse markers across the class periods will be focused. First all, the discourse markers used in utterance units are calculated in the periods or teachers and are analyzed quantitatively and qualitatively, and then according to our observations and interviews after recording, the functions of several most frequently used markers as OK, Yeah, Now, 好 (Good) will be discussed, lastly, the conclusion will be made to summarize the use of discourse makers in teacher's code-switching.

\section{Methods AND Procedures}

\subsection{Sampling Classes and Subjects}

English classes were chosen from grade two in junior classes and senior classes in 2013-2014 academic years. Ten of English teachers of two different grades were asked to participate in this project and nineteen of their lessons were observed and audio-taped. In the pilot researches (Yao \& Zeng 2006a, b), some code choices were motivated by simple lexical gaps (that is, sometimes, teachers switch to another language simply because they cannot think of the appropriate lexical items in one language). In addition to that, it is reasonable to expect that teachers' code switches are motivated by other factors, such as the students' language ability, teachers' own experience, the difficulty of the tasks, the type of the lesson (text lesson, exercise lesson, listening etc). All the teachers switch intentionally and their switches to Chinese are intended to reach communicative and pedagogical goals.

Among those teachers participating this study, half are junior teachers and half senior teachers, four are males and six females for comparison, two class periods (one period is 45 minutes) for each teacher are recoded, yielding a total of 19 periods of classroom discourse data. 


\subsection{Recording the Classes}

All the class sessions observed in the second semester were audio-taped (All the research data were collected using audio tape recorders). The purpose for audio-taping sessions was twofold: First, a more complete record of the interactions between teachers and students, especially teachers utterances. Second, during the interviews the audiotapes were used to help teachers remember what they had said, thought, and felt in class. The recording was divided into two stages of time, one for each period about 3 months of interval. During the observation and recording, teachers were just told that the goal of observing their classes was to pursue the way in which language was used in English language classes. This was to avoid conscious code-switching on one hand or, on the other hand, to prevent the avoidance of spontaneous use of students' native language.

\subsection{Transcribing and Coding the Recordings}

Every utterance of the classes was transcribed as possible as we can, although the research mainly focused the teachers' utterances. Some symbols were used to represent the teachers and students who were identified by the $\mathrm{T}(\mathrm{T}=1,2,3 \ldots . .10)$ and $\mathrm{S}$ or $\mathrm{Ss}$ respectively. Some features such as laughs, gestures, intonation, volume and interruptions in transcriptions were complemented by ethnographic notes in remedying the defect of not providing the facial expressions of the teachers and students. The transcription conventions were referred to conventions in works of Arthur (1996), Heller \& MartinJones (2001), Flood, et al. (1997), and Lisa (2003) and some ideas were based on Baker (1997).

According to others' researches and our observation, the teachers' talk are divided into units of utterance and the units are categorized into four types labeled as $(\mathrm{E}) ;(\mathrm{C}) ; \mathrm{E}(\mathrm{C}) ; \mathrm{C}(\mathrm{E})$ based on Myers-Scotton's MLF model (1993b): (E) refers to the utterance completely in English; (C) refers to the utterance completely in Chinese; $\mathrm{E}(\mathrm{C})$ indicates that the utterance is in the target language (English) with one word or phrase in Chinese embedded and C (E) refers to the utterance in Chinese with one word or phrase in the target language (English).

Once identified and coded, discourse markers were categorized according to the functions used by teachers, then the number of those markers is counted in each period.The transcripts are analyzed numerically and qualitatively according to the different markers (such as yeah, ok, good etc.) and the functions which these markers fulfilled.

All the discourse analysis is based on transcriptions of the audio tape recordings. Utterance units with Chinese will be translated into English when they are analyzed. The original transcriptions are presented immediately after each extract for analytical purposes and to facilitate the text for readers. The ethnographic approach of the whole project is to have helpful information about the classroom context for the interpretation.

\section{Discourse Markers in TeaChers' CODE-SWITCHING}

The following tables display the distribution of several major discourse markers used in nineteen class periods or by teachers. Of the total of 893 markers which trigger code alternation in the nineteen periods, four major markers mentioned above account for 715 cases, occupying eighty percent of the total. Table1 gives the number of occurrences of discourse markers in unit initial position in the data, while Table 2 presents the markers used by teachers. What table1 illustrates clearly is the wide range in the frequency of discourse markers used in the periods, from the 14.8 percent of the total in the highest case in data 16 , to 0.6 percent, the lowest case in data 1 . Table 2 shows that the most frequently used marker is Now, while the least frequently used marker is Chinese marker 好 (good). Table 3 and Chart 1 display the details of the frequency and percentages of the four major discourse markers used by teachers.

Table1. Distribution of discourse markers in the nineteen-period sample

\begin{tabular}{|c|c|c|c|c|c|c|}
\hline & Ok & Now & Yeah & 好(Good) & Total & Percent (\%) \\
\hline D 1 & $\mathbf{4}$ & $\mathbf{0}$ & $\mathbf{0}$ & $\mathbf{0}$ & $\mathbf{4}$ & $\mathbf{0 . 6}$ \\
\hline D2 & 14 & 18 & 3 & 17 & 52 & 7.3 \\
\hline D3 & 16 & 12 & 6 & 8 & 42 & 5.9 \\
\hline D4 & 5 & 15 & 16 & 0 & 36 & 5.0 \\
\hline D5 & 0 & 8 & 1 & 0 & 9 & 1.3 \\
\hline D6 & 5 & 12 & 9 & 2 & 28 & 3.9 \\
\hline
\end{tabular}


Discourse Markers as Triggers of Code-switching in EFL Classes

\begin{tabular}{|c|c|c|c|c|c|c|}
\hline \hline D7 & 21 & 16 & 10 & 15 & 62 & 8.7 \\
\hline D8 & 3 & 10 & 1 & 0 & 14 & 2.0 \\
\hline D9 & 33 & 8 & 2 & 22 & 65 & 9.1 \\
\hline D10 & 15 & 6 & 1 & 12 & 34 & 4.8 \\
\hline D11 & 3 & 18 & 0 & 7 & 28 & 3.9 \\
\hline D12 & 26 & 11 & 4 & 0 & 41 & 5.7 \\
\hline D13 & 21 & 10 & 7 & 1 & 39 & 5.5 \\
\hline D14 & 2 & 19 & 4 & 0 & 25 & 3.5 \\
\hline D15 & 3 & 2 & 0 & 1 & 6 & 0.8 \\
\hline D16 & 21 & 2 & 80 & 3 & 106 & 14.8 \\
\hline D17 & 13 & 8 & 19 & 9 & 49 & 6.9 \\
\hline D18 & 2 & 25 & 2 & 5 & 34 & 4.8 \\
\hline D19 & 7 & 23 & 7 & 4 & 41 & 5.7 \\
\hline Total & $214(30 \%)$ & $223(31 \%)$ & $172(24 \%)$ & $106(15 \%)$ & $715(100 \%)$ & $100 \%$ \\
\hline
\end{tabular}

Table2. Distribution of discourse markers in the teacher sample

\begin{tabular}{|c|c|c|c|c|c|c|}
\hline & Ok & Now & Yeah & 好 & Total & Percent (\%) \\
\hline T1 & 4 & 0 & 0 & 0 & 4 & 0.6 \\
\hline T2 & 30 & 30 & 9 & 25 & 94 & 13.1 \\
\hline T3 & 5 & 15 & 16 & 0 & 36 & 5.0 \\
\hline T4 & 5 & 20 & 10 & 2 & 37 & 5.2 \\
\hline T5 & 24 & 26 & 11 & 15 & 76 & 10.6 \\
\hline T6 & 51 & 32 & 3 & 41 & 127 & 17.8 \\
\hline T7 & 47 & 21 & 11 & 1 & 80 & 11.2 \\
\hline T8 & 5 & 21 & 4 & 1 & 31 & 4.3 \\
\hline T9 & 34 & 10 & 99 & 12 & 155 & 21.7 \\
\hline T10 & 9 & 48 & 9 & 9 & 75 & 10.5 \\
\hline Total & $214(30 \%)$ & $223(31 \%)$ & $172(24 \%)$ & $106(15 \%)$ & $715(100 \%)$ & $100 \%$ \\
\hline
\end{tabular}

Table3. Frequency of discourse markers

\begin{tabular}{|l|l|c|c|c|}
\hline & Frequency & Percent & Valid Percent & Cumulative Percent \\
\hline Valid & 好(Good) & 106 & 14.8 & 14.8 \\
\hline & Yeah & 172 & 24.1 & 24.1 \\
\hline & Now & 214 & 29.9 & 29.9 \\
\hline & Ok & 223 & 31.2 & 31.2 \\
\hline & Total & 715 & 100.0 & 100.0 \\
\hline
\end{tabular}
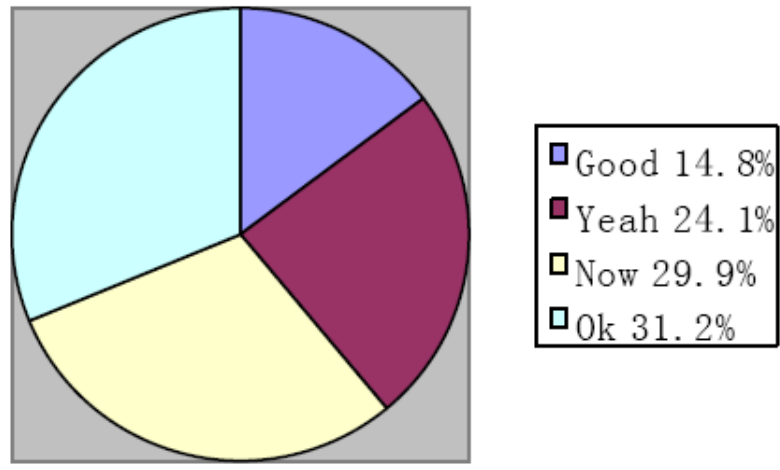

Chart1. Pie chart of frequency of four discourse markers

\section{Functions of Discourse Markers as Triggers to Switch CODES}

Four categories are identified to denote different marker usages: first, single word acknowledgements, such as Okay, right, yes, yeah; second, interjections with discourse purposes, such asoh, well, mm; third, coordinating conjuncts used as discourse markers, such as so ,but; last, adverbials used as discourse markers, such as then, now, first. Here we only focus several markers frequently used teachers in the data: three English discourse markers, Ok(ay), Yeah, and Now, and one Chinese discourse marker 好(good). All the above discourse markers are in unit-initial positions and may trigger code switches in upcoming utterances. 


\subsection{The Functions of $O k$ (ay) in Teachers' Talk}

Okay has a rather informal status in spoken English, but it can have many uses in spoken dialogue systems, depending on the level of formality required for the service. According to Stenstrom (1994), he assigns various functions to Okay depending on its location within an utterance. Okay at the beginning of a turn expresses agreement, and can also indicate acknowledgement of the preceding utterance. Okay in second position following "yes" emphasizes the agreement expressed by "yes". However, that role depends on the intonation of the utterance. For example, "Yes, OK" (spoken with a sigh) potentially indicates reluctant agreement or consent. On the other hand, "Yes, OK" (spoken with stress on Okay) indicates impatience with the interlocutor. Okay within the turn finishes a topic, and Okay at the end of a turn asks for confirmation (Again depending on intonation). Here, we only analyze those which are in unit-initial position.

Re-examining table 1 andtable 2, there are important differences between the periods or teachers in using Okay. T6 and T7 use Ok(ay) more frequently than other teachers, accounting for 51 units and 47 units respectively, while in Data 5, no single Okay used by T4 is found at all.

In the data, most initial unit OKs are used to trigger to code switch for expressing agreement or indicating acknowledgement of the preceding utterance, as Stenstrom (1994) points out. 'OKs' in the following extracts indicate that the teachers acknowledge what he or she just uttered or the student responded. English marker $O K$ usually triggers marked switches from Chinese to English. For example(italicized part in brackets is translation):

Extract 1

D1-303 T: 他旅游的路线怎么样(what about his travel route?) C EL

D1-304 OK, read this passage, the last part and fill the blank E CM

We also find some cases in which $O K$ triggers marked switches by the same teacher or other teachers.

Extract 2

D2-680 T: Yeah, Study at home with somebody E CL

D2-681 OK, 第十一题(eleventh) C (E) CM

Extract 3

D9-081 S: (xxx)

D9-082 T: Ok！前面很不错, 后面稍微停了一下(the first part is very good, but there is a pause in the last part) $\mathrm{C}$ (E) $\mathrm{PR}$

And switched utterances can function as other different moves: suggest action; request action, request validation; request information and elaborates-repeats. For example:

Extract 4

D9-429 T: Mr. Bean, 憊豆先生（Mr. Bean） E（C） CL

D9-430 OK, 大家看下他的表情（everybody looks at his expression） C（E） CM

(Suggest action)

Extract 5

D9-550 $\mathrm{T}$ : 喜剧, 不是喜剧演员, 是整个剧本让人发笑 (comedy, not comedian, is the whole play that makes people laugh) (C) CL

D9-551 OK, The second one is? (...) (E) EL

(Request validation)

Extract 6

D9-099 T: 就是有一个快乐的农民在场吗? （is that 'is there a pleasant peasant present?)'

(C) EL 

D9-100
Ok, repeat this sentence.
(E) $\mathrm{CM}$

(Request action)

D9-099 T: (C) EL

D9-100 Ok, repeat this sentence. (E) CM

Extract 7

D9-140 T: 注意它的念法（Pay attention to it pronunciation） E(C) CM

D9-141 OK, now, next question (E) CM

(Request information)

Extract 8

D12-162 T: OK, 如果不是绝对的没有关系, 可能是只有一部分有关 (if it is not absolutely unrelated, maybe it is partially related ) , C(E) CL

D12-163 Has something to with something, OK? E EL

D12-164 OK, 至少不是完全相关性（at least it is not completely related） C (E） CL

(Elaborates-repeats)

\subsection{The Functions of 'Yeah' in Teachers' Talk}

All the teachers except T1 use the discourse marker yeah in their classes. Table 1 and Table 2 display the distribution of yeah in period and teacher sample. there are also important differences between teachers or periods. For instance, it seems that T9 particularly preferred to use more yeahs than other teachers, whereas T1 didn't use one at all during the whole period.

The discourse markers Yeah or Yes (and variations like yup which is not found in our corpus) can play many different roles in teachers' discourse. As such yeah serves as a particularly useful illustration of how to decide among speech utterance types, how to recognize fillers (in this case discourse markers) that are included within larger speech utterances rather than acting as speech utterances of their own.

In the data, initial unit 'Yeah' is also used to express agreement or indicate acknowledgement of the preceding utterance and as a trigger to code-switch for eliciting a response or repeat or explain the prior utterance, as the following examples show:

Extract 9

D3-013 S: Argue, a-r-g-u-e, argue, 争吵( argue)

D3-014 T:争吵(argue) C RE

D3-015 Yeah, now, next, 打电话给某人(call somebody) E(C) EL

Extract 10

D4-276 T: the father of science fiction $E$ RE

D4-277 科幻小说之父(the father of science fiction) C RE

D4-278 Yeah, so you should know him E CM

Discourse marker yeah can also be invoked to provide a (positive) reaction, affirmation, or endorsement of something the other speaker has said, in which case it is tagged as a discourse response. Providing a (positive) reaction is usually followed by students' correct response:

Extract 11

D4-630 T: now 许振(Xu Chen), translate $\mathrm{E}(\mathrm{C}) \mathrm{CM}$

D4-631 Yeah,再见面还要很久(how long we will meet again) $\mathrm{C}(\mathrm{E})$ EL

Discourse marker yeah can serve to affirm to the speaker's own statement, for example:

Extract 12

International Journal on Studies in English Language and Literature (IJSELL) 
D16-043 T: to practice these tongue twisters, We can pronounce the words correctly (E) CL

D16-044 yeah, 通过练习这些绕口令, 我们可以正确发音 (by practicing these tongue twisters, we can pronounce correctly) C (E) RE

Sometimes the speaker endorses something that the other speaker has said. For example:

Extract 13

D3-172 T: 能不能(can we say) ask a problem? E(C) EL

D3-173 Ss:不能(No)

D3-174 T: Yeah, ok, now, is it serious or not? E EL

Yeah sometimes serves as a direct response to a question, in which case, it should be tagged as a statement speech utterance, only if said question is querying a response, not merely querying a feedback.

Extract 14

D16-230 T: 看到没有啊？(do you see?)（C） EL

D16-231 yeah 这里有六幅图, 是不是? (yeah here there are six pictures, aren't there?)（C) EL

\subsection{The Functions of 'now' in Teacher's Talk}

The most frequent use of discourse marker in our corpus is 'Now' which accounts for 223 cases, occupying 31 percent of the total. All the teachers except T1 used 'Now' as a trigger to code-switch in their talk. There are also important differences between teachers, among whom T10 preferred to use more 'Nows' than other teachers. Following Schiffrin(1987:230), "now" is a deictic element that "marks a speaker's progression through discourse time, by displaying attention to an upcoming idea, unit or orientation and/or participation framework" (230). Here, it is important, however, to distinguish ' $n o w$ ' as a discourse marker or conjunctive element from the adverb 'now'. The adverbial refers to "the time at which a proposition is present to be true", whereas the discourse marker 'now" "occurs in discourse in which the speaker progresses through a cumulative series of subordinate units" (Schifrin 1987:228). Here we are interested in the discourse marker 'Now' which triggers the codeswitching in teacher's talk. First, teachers use 'now' to mark his teaching progression through discourse time. In the following extract, 'now' can mark an orderly progression through a sequence of subordinate parts, and 'now' marks one part of that sequence.

Extract 15

D2-215 T: 这个句型(This pattern drill)What do you think Shine will be in five years C (E) CL

D2-216 这个句型要掌握(This pattern drill should be grasped) C CM

D2-217 I think she will be a doctor E CL

D2-218 Ok, group one, group one E CM

D2-219 有更多的高楼大厦(there will be more high buildings) C CL

D2-220 Now, write down. <The teacher writes the sentence on the blackboard> E CM

D2-221 There will be more buildings E CL

Second, As Ball (1986:85) points out, "now is transitional, frequently the opening word from a new speaker, but the same speaker can use it to indicate a new idea or stage with a topic" (Ball1986:85). That is, now can be as a marker of transition in thematic progression. In classroom interactions, teachers would often use now to indicate a new topic or task. In the following extract, after explaining some grammatical points, the teacher uses the discourse marker now as a trigger to switch code to target language, indicating another task for the students.

Extract 16

D5-053 T: 'Should' do you know? E EL 


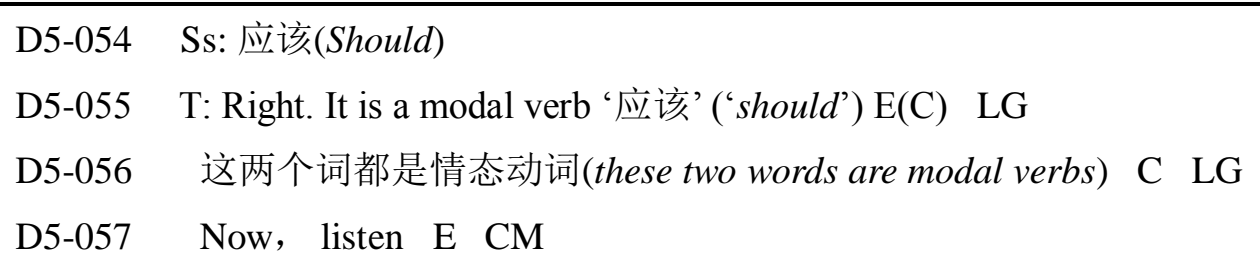

Finally, overlapping with the second one, the teachers employ now to display attention to an upcoming idea. As Grosz and Sidner (1986) explains, now marks an attentional change, creating a new focus space of salient objects and topics. For example:

\section{Extract 17}

D3-506 T: Ah, you should, you could, 对不对(isn't it)? E(C) EL

D3-507 啊,这两个词语气会稍有不同(Ah, the two words have a little difference in mood) C LG

D3-508 Now, please, 看到(look at)grammar focus C(E) CM

D3-509 What should I do? E EL

D3-510 啊, 我该怎么办(Ah, what should I do)? C RE

:

D3-537 Now, please, 翻过来(turn back), 3A C (E) CM

D3-538 Make a conversation E CM

D3-539 What do you think of advice? E EL

However, there are cases where the speaker does not explicitly utter an introduction topic at the beginning of the segment, with the result that the attention-shifting now is attached to the initial topic. For example:

Extract 18

D3-051 S: c-o-u-1-d

D3-052 T: Could, yeah, sit down E CM

D3-053 能,能.啊(can, can, Ah) C CL

D3-054 Should E CL

D3-055 OK, everyone, let's learn the new lesson, Unit 2 E CM

D3-056 What should I do, should <On the blackboard>, Should E EL

D3-057 Ss:应该(should)

D3-058 T: 应该,应该(should should) C RE

D3-059 Now, we have learned E CL

D3-060 we have learned E RE

D3-061 啊, 我们学过的, 是吧(Ah, we have learned it, haven't we)? $\mathrm{C}$ RE

\subsection{The Functions of '好'(good) in Teachers' Talk}

As a discourse marker, hao can occur in different positions and indeed has different syntactic functions. Looking at hao based on spoken database, Miracle (1991) finds that hao not only (i) plays a role in the development and closure of the commissive/requestive social actions, but also (ii) serves to make assertions or mark a transition to a new topic or social activity, (iii) marks the closure of telephone calls or other physical activity, and (iv) when used within a particular speaker's turn, functions as a marker of idea management of signaling a completion of prior topic or activity and a transition of another topic or activity.

In teacher's discourse, Hao mainly serves to make assertions or mark a transition to a new topic or task, usually in a different code or mark the closure of particular task and a transition to another task. 
Extract 19

D2-060 T: 把它写下来(write it down) C RE

D2-061 好(good), next, 1-c,1-c E(C) CM

Extract 20

D3-615 T: either用于否定句或疑问句的句尾(is used in the end of negative or question sentence) C (E) LG

D3-616 好,举个例子啊(Good, take an example) C CM

The unmarked use of hao is followed by Chinese utterances; however teachers tend to use English words or mixed codes after hao. Among 106 cases of hao used in the corpus, 59 cases of hao are followed by English utterances.

Extract 21

D6-266 T: OK, sit down E CM

D6-267 好, 这段翻译起来比较困难 (Good, it is more difficult to translate this paragraph)

C $\mathrm{CM}$

Extract 22

D5-298 T: Like doing something $\mathrm{E} \quad \mathrm{RE}$

D5-299 好(Good), the last one E(C) CM

From the data, teachers used more marked utterances than unmarked ones. It is suggested that teachers try to use less marked utterances as possible as they can.

\section{Conclusion}

In EFL classes, teachers employ a lot of discourse markers. It is found that discourse markers can trigger code-switching. Four major discourse markers have been described and their functions have been discussed. Other discourse markers also play a very important role in teaching. The disappearance or appearance of some classroom discourse markers are connected with the particular contexts of classroom discourse. They are made and organized socially and culturally, so they must be interlaced with society and the culture of the society. In EFL classes, each discourse marker may have different functions in process of teacher as they are described in the above sections, and different discourse markers may have the same function in teachers' discourse.

\section{REFERENCES}

Adendorff, R. 1993. Code-switching amongst Zulu-speaking teachers and their pupils: Its functions and implications for teacher education. Language and Education 7(3):141-161.

Auerbach, E. 1993. Re-examining English only in the ESL classroom. TESOL Quarterly 27(1): 9-32.

Canagarajah, S. 1996. Functions of code-switching in ESL Classrooms: Socializing Bilingualism in Jaffna. Journal of Multilingual and Multicultural Development 13(1-2):173-195.

Cazden, C.B. 1988 (2001). Classroom Discourse: the Language Teaching and Learning. Portsmouth, NH: Heinemann.

Chamber, F. 1991. Promoting use of the target language in the classroom. Language Learning Journal 4:27-31.

Crookes, G. 1990. The utterance and other basic units for second language discourse analysis. Applied Linguistics 11: 183-199.

Duff, P. A. \& Polio, C. G. 1990. How much foreign language is there in the foreign language classroom? Modern Language Journal 74:154-166

Ferguson, G. 2003. Classroom code-switching in postcolonial contexts: Functions, attitudes and polices. AILA Review 16:38-51.

Giles, H \& Powesland, P. F. 1975. Speech Style and Social Evaluation. London: Academic Press.

Hancock, M. 1997. Behind classroom code switching: Layering and language choice in L2 learner interaction. TESOL Quarterly 31(2):217-235. 
Hussein, Riyad F. 1999. Code-alteration among Arab college students. World Englishes 18(2):281289.

Johnson, K. 2001. An Introduction to Foreign Language Learning and Teaching. Arkansas: Pearson Education Limited.

Kramsch, C. 1985. Classroom interaction and discourse options. Studies in Second Language Acquisition7:169-183.

Lisa, M. S. 2003. Functions of Code-switching in Classes of German as a Foreign language. Unpublished dissertation, University of Texas, Austin, Texas.

Macaro, E. 2001. Analyzing student teachers' code-switching in foreign language classrooms: Theories and decision making. Modern Language Journal 85: 531-48.

Merritt, M. et al. 1992. Socializing multilingualism: Determinants of code-switching in Kenyan primary classrooms. Journal of Multilingual and Multicultural Development 13(1/2): 103-121.

Miracle, W. C. 1991. Discourse Markers in Mandarin Chinese. Unpublished doctoral dissertation. The Ohio state university.

Moore, D. 2002. Case Study: Code-switching and learning in the classroom. International Journal of Bilingual Education and Bilingualism 5(5):279-293.

Nizegorodcew, A. 1996. The function of the native language in foreign language teacher-learner interaction. In K. Sajavaara \& C. Fairweather eds. Approaches to Second Language Acquisition. Jyvaskyla, Finland: University of Jyvaskyla.

Polio, C. G. \& Duff, P. A. 1994. Teachers' language use in university foreign language classroom: A qualitative analysis of English and target language alternation. Modern Language Journal 78:313-326.

Redeker, Gisela, 1991, Linguistic markers of discourse structure. Linguistics29: 1139-1172.

Schiffrin, D. 1987. Discourse Markers. Cambridge: Cambridge UP.

Seedhouse, P. 2004. The interactional architecture of the language classroom: A conversation analysis perspective. Language Learning 54:18-32.

Simon, D. 2001. Towards a new understanding of code-switching in the foreign language classroom. In Jacobson, D. ed. 2001. Code-switching worldwide II. Berlin, New York: Mouton de Gruyter.

Sinclair, J. M. \& Coulthard, R. M. 1975. Towards an Analysis of Discourse: The English Used by Teachers and Pupils. London: Oxford University Press.

Stenstrom, Anna-Brita. 1994. An Introduction to Spoken Interaction. London: Longman

Wu Yi'an. 1985. Code-mixing by English-Chinese bilingual teachers of People's Republic of China. World Englishes 4(3):303-317.

Yao, Mingfa \& Zeng Caijin. 2006a. Functions of Chinese in secondary EFL classroom in China. SinoUS English Teaching 31: 38-42.

Yao Mingfa \& Zeng Caijin. 2006b. Functional analysis to teachers' code-switching in secondary EFL classroom. Guangxi Social Science 10:151-154.

Yao Mingfa. 2007. The development and reflection on code-switching theories in the last 50 years. Guangxi Social Science 3:149-153.

Yu Guodong. 2001. Pragmatic Approach to English/Chinese Code-switching. Shanxi People Publication Press. 